\title{
A SUPERVISÃO DE ENSINO COMO INDUTORA DO FORTALECIMENTO NA FORMAÇÃO CONTINUADA DOS PROFISSIONAIS DA EDUCAÇÃO DA REDE PÚBLICA ESTADUAL PAULISTA
}

\author{
LA SUPERVISIÓN DE LA EDUCACIÓN COMO INDICADOR DE \\ FORTALECIMENTO EM LA FORMANCIÓN DE LOS PROFESIONALES DE \\ EDUCACIÓN PÚBLICA DEL ESTADO PAULISTA
}

\begin{abstract}
THE SUPERVISION OF TEACHING AS AN INDUCTOR OF THE STRENGTHENING IN THE CONTINUING EDUCATION OF EDUCATION PROFESSIONALS OF THE SÃO PAULO STATE PUBLIC NETWORK
\end{abstract}

Chelsea Maria de Campos MARTINS ${ }^{1}$

Paulo César CEDRAN ${ }^{2}$

RESUMO: O artigo tem por objetivo investigar a contribuição do supervisor de ensino ao analisar à importância da sua ação e em que medida provoca nos profíssionais da educação reflexão da proposta de formação continuada oferecida pela Rede Pública Estadual Paulista. Trata-se de uma discussão com vistas apreender e analisar os desafios postos ao supervisor de ensino na gestão de formação continuada aos profissionais da educação desta rede pública. Conclui-se que os desafios em voltas da ação supervisora junto a formação dos profissionais da educação pode contribuir para a melhoria da qualidade de ensino oferecido aos alunos das escolas públicas, uma vez que ao acesso e permanência na escola pública já foram garantidos quase em sua totalidade e pode fortalecer o oferecimento de uma escola com mais qualidade de ensino.

PALAVRAS-CHAVE: Supervisão de ensino. Formação continuada. Profissionais da educação.

RESUMEN: El artículo tiene como objetivo investigar la contribución del supervisor docente al analizar la importância de su acción yen qué medida provoca en los profesionales de la educación la reflexión sobre la propuestade educación continua que oferece la red pública estatal de São Paulo. Es uma discusión dirigida a prehender y analizar los desafios planteados al supervisor de la enseñanza em la gestión de la educación continua para los profesionales de la educaciónde esta red pública. Se concluye que los desafios que rodean la acción de supervision con los profesionales de la educación pueden contribuir a la mejora de la calidad de la educación oferecida a los estudiantes de las escuelas públicas, ya que el accesoy la permanencia em la escuela pública estaban casi garantizados y puede fortalecer la provisión de uma escuela de mayor calidad.

${ }^{1}$ Universidade Estadual Paulista (UNESP), Marília - SP - Brasil. Doutoranda no Programa de Pós-graduação em Educação. ORCID: https://orcid.org/0000-0002-9984-219X. E-mail: chelseamcmartins@yahoo.com.br

${ }^{2}$ Centro Universitário Moura Lacerda, Jaboticabal - SP - Brasil. Docente no Curso de Educação Física e Supervisor de Ensino/SEE/SP. Doutorado em Educação Escolar (UNESP). ORCID: https://orcid.org/0000-00019941-8690. E-mail: pccedran@gmail.com

RIAEE - Revista Ibero-Americana de Estudos em Educação, Araraquara, v. 15, n. esp. 4, p. 2777-2788, dez., 2020. e-ISSN: 1982-5587 
PALABRAS CLAVE: Supervisión docente. Educación continua. Profesionales de la educación.

ABSTRACT: The paper aims to investigate the contribution of the teaching supervisor when analyzing the importance of its action and to what extent it provokes in education professionals a reflection on the proposal of continuing education offered by the São Paulo State Public Network. It is a discussion aimed at apprehending and analyzing the challenges posed to the teaching supervisor in the management of continuing education for education professionals of this public network. It is concluded that the challenges of the supervisory action in the formation of education professionals can contribute to improving the quality of education offered to students in public schools, since access to and permanence in public schools have already been guaranteed almost in its entirety and can strengthen the offer of a school with higher quality teaching.

KEYWORDS: Teaching supervision. Continuing education. Education professionals.

\section{Introdução}

A supervisão de ensino da Rede Pública Estadual Paulista atua por meio de várias ações a saber: em visitas nas escolas supervisiona, fiscaliza e ao mesmo tempo providenciando correções de falhas administrativas e pedagógica, avalia sob pena responsabilidade. Também, oferece assessoria, acompanha, orienta, avalia e controla os processos educacionais implementados nas diferentes instâncias pela rede pública estadual paulista. Outra contribuição significativa deste profissional é a de realizar estudos e pesquisas, dar pareceres e propor ações voltadas para o desenvolvimento desta rede, conforme estabelecido no artigo 74 -Decreto $\mathrm{n}^{\circ}$ $64.187 / 2019$.

Tal contribuição deste supervisor de ensino se deve ao fato de que hoje, em propiciar as condições de formação dos profissionais de educação (equipe gestora e corpo docente) bem como as condições da própria formação - inicial e continuada, para atender, igualmente, às exigências que o mundo da informação e do conhecimento nos apresenta como desafios.

Tempo de aprendizado. Seja por maior tempo na escola, seja por vivências que respondam às questões postas pela vida, escolar, o aprendizado, tanto dos professores quanto dos alunos ganha em qualidade se a estrutura material, humana e simbólica está coerentemente articulada para a produção de uma qualidade social da educação (PRADO, 2009, p. 47) .

${ }^{3}$ Frase extraída do minicurso - 6 Ensino Fundamental de nove anos: currículo e expectativas de aprendizagem PRADO, Guilherme do Val Toledo - VII Simpósio do Laboratório de Gestão Educacional -LAGE, realizado em 23 de maio de 2009, Campinas, SP:FE/UNICAMP.

RIAEE - Revista Ibero-Americana de Estudos em Educação, Araraquara, v. 15, n. esp. 4, p. 2777-2788, dez., 2020. e-ISSN: 1982-5587 
Nesta perspectiva, o presente artigo tem por objetivo investigar a contribuição da atuação do supervisor de ensino ${ }^{4}$, analisar a importância desta atuação como nas visitas escolares $^{5}$ referente às escolas estaduais, no contexto das Diretorias de Ensino Regionais, que compõem a Rede Estadual de Ensino Paulista, no sentido de provocar nos profissionais da Educação (direção, vice direção, coordenador pedagógico e professores) a reflexão da proposta de formação continuada proporcionada por esta rede ${ }^{6}$, desencadeada a partir da mudança com o Currículo Oficial do Estado de São Paulo estabelecido com a finalidade da melhoria de qualidade do ensino oferecido bem como no atendimento ao corpo discente ${ }^{7}$.

\section{Análise da contribuição das Políticas Públicas}

Para nossa discussão é relevante considerar a redescoberta da educação na agenda das políticas públicas nos últimos anos e que está inserida no contexto de reestruturação da sociedade capitalista, decorrente da globalização da economia e da difusão do conhecimento. O contínuo processo de modernização aponta para o redirecionamento do papel da escola e sua função social (VIEIRA, 2001).

Nesse sentido, acrescentamos a preocupação com o monitoramento e as condições de:

[...] qualidade a serem consideradas como referência analítica e política no tocante à melhoria do processo educativo e, também, à consolidação de mecanismos de controle social da produção, à implantação e monitoramento de políticas educacionais e de seus resultados, visando produzir uma escola de qualidade socialmente referenciada (DOURADO; OLIVEIRA, 2009, p. 207).

Para melhor entendimento dos rumos traçados para as reformas educacionais empreendidas nos últimos anos, cabe citar os principais fatos que marcaram o debate educacional internacional: Conferência Mundial de Educação para todos (1990), Conferência de Nova Delhi (1993), Projeto Principal de Educação da América Latina e do Caribe (1996).

\footnotetext{
${ }^{4}$ Supervisor de sistema: na busca de uma construção de um arquétipo flexível adequado em sua contribuição para e na formação continuada dos profissionais da educação (equipe gestora e corpo docente).

${ }^{5}$ Conforme estabelece a Lei Complementar $\mathrm{n}^{\circ} .744$, de 28 de dezembro de 1993, no artigo $9^{\circ}$ inciso I compete ao supervisor de ensino exercer, por meio de visita aos estabelecimentos de ensino, a supervisão e a fiscalização das unidades escolares incluídas no setor de trabalho que lhe for atribuído, prestando a necessária orientação técnica e providenciando a correção de falhas administrativas e pedagógicas, sob pena de responsabilidade.

${ }^{6}$ Progestão, TICs, Letra e Vida, Programa Ler e Escrever, Teia do Saber, Ensino Médio em Rede, Programa REDEFOR entre outros cursos bem como a capacitação oferecida nas Diretorias de Ensino Regionais pela Oficina Pedagógica e Supervisão de Ensino ou cursos oferecidos em parcerias com as universidades.

${ }^{7}$ Considerando a função do servidor público como sendo aquele que serve o outro e este atendimento com qualidade e ainda com projeção de resultado positivo de aprendizagem, em especial, para o aluno.
} 
No entanto, o marco divisor de águas foi a Conferência Mundial de Educação para todos, realizada em Jomtien, Tailândia, em março de 1990, sob o patrocínio da Organização das Nações Unidas para a Educação, Ciência e Cultura (UNESCO), Fundo das Nações Unidas para a Infância (UNICEF), Programa das Nações Unidas para o Desenvolvimento (PNUD) e Banco Mundial (BIRD).

De acordo com Sander (1995) esta conferência sintetizou o consenso políticopedagógico adotado pelos governos nos últimos anos no sentido de compromisso com a universalização (equidade) da educação básica de qualidade para todos.

Nessa perspectiva, Casassus (1995) coloca que os anos 90 foram marcados por ampla reforma no setor público, visando o reexame do papel do Estado, com ênfase na gestão pública. No setor educacional, a descentralização da gestão escolar aparece como estratégia para as reformas dos sistemas educativos, visando à melhoria da qualidade de ensino.

A esse respeito, Libâneo (2008) considera que as políticas educacionais têm se centrado na escola como unidade básica e espaço de realização dos objetivos e metas do sistema educativo, porque:

As políticas educacionais em âmbito internacional passam por intensas mudanças, visando ajustá-las às demandas da atual fase do capitalismo, conforme necessidades e realidades de cada país. A ordem é sintonizar os sistemas educacionais ao modelo neoliberal. A tendência das reformas educativas é de reagregar a educação à economia, numa versão modificada em relação ao que propunham os economistas da educação a partir dos anos 50 coma chamada "teoria do capital humano" (LIBÂNEO, 2008, p. 241).

Assim, a política educacional brasileira, a partir da segunda metade da década de 80, esteve orientada para mudanças nos padrões de gestão, com ênfase na descentralização, visando prover os municípios e/ou unidades escolares de autonomia, com objetivo de elevar os padrões de eficácia e eficiência que pudessem garantir uma ação educacional efetiva, ou seja, assegurar a permanência e a aquisição de aprendizagens básicas à maioria dos alunos (CABRAL, 1997).

\section{A formação continuada dos profissionais da educação na gestão da Rede Pública Estadual Paulista}

Em conformidade com esse momento da educação brasileira, na Gestão da Educação do Estado de São Paulo, a partir de 1995, ocorreu ampla reforma educacional definida com ênfase em três eixos fundamentais: a racionalização organizacional, mudanças nos padrões de gestão, com ênfase na descentralização e desconcentração do poder de decisão para órgãos locais e unidades escolares e melhoria da qualidade de ensino (NEUBAUER, 1996). 
O conjunto de medidas propostas e ações implantadas no período em questão constituíram-se em impacto para a gestão escolar, pois as mudanças foram profundas, exigindo um repensar da escola desde os conceitos de ensino-aprendizagem, dos processos de avaliação e principalmente, do dirigir a unidade escolar para atingir os objetivos de construção da aprendizagem dos alunos.

Em consonância com o processo de implementação da reforma educacional desencadeada a partir de 1995 pela Rede Pública Estadual Paulista, o diretor de escola e o supervisor de ensino participaram de uma série de ações voltadas para a formação continuada para os gestores do sistema de ensino público estadual.

Desse modo, em 2000, foi implantado o Circuito Gestão, programa criado com o objetivo de fortalecer as lideranças da educação, através da educação continuada para gestores da Rede Pública Estadual Paulista manifestando vontade política de fortalecer, institucionalmente, o sucesso da escola democrática e inclusiva.

Tal programa foi estabelecido a partir de um projeto do Centro de Capacitação de Gestores, implantado por esta rede pública, na gestão da secretária professora Rose Neubauer, sob a coordenação da educadora Raquel Volpato Serbino. Foram instalados nove Centros para Formação dos Gestores (CENFORGEST) em diversas cidades do interior (Bebedouro, Botucatu, Ilha Solteira, Monte Aprazível, Osvaldo Cruz, Porto Ferreira, Registro, Santa Cruz e São Vicente). Os cursos foram ministrados em forma de módulos, tendo iniciado em agosto de 2000

Na gestão do professor Gabriel Chalita, encerrado o Programa Circuito Gestão, teve início, em 2004 o Programa de Capacitação a Distância para Gestores Escolares - Progestão. O referido programa teve por objetivo "formar lideranças comprometidas com a construção de um projeto de gestão democrática focada no sucesso escolar dos alunos das escolas públicas do ensino fundamental e médio".

Ao contrário do Circuito Gestão, em que os diretores de escola deslocavam-se até os vários polos de formação, a sistemática adotada pelo Progestão foi a capacitação centralizada de tutores (supervisores de sistema) e, depois, descentralizada, para os diretores de escola e supervisores de sistema, nas Diretorias Regionais de Ensino. Outro dado foi que este programa constitui-se em parceria com o CONSED e outras Secretarias de Educação.

Em 2005, a Rede Pública Estadual Paulista em parceria com a Universidade Estadual de Campinas - UNICAMP, concomitante ao Progestão, ofereceu aos diretores escolares, supervisores de ensino e dirigente de ensino o Curso de Especialização em Gestão Educacional, semipresencial, a ser encerrado em 2006. 
No primeiro semestre de 2010, Rede Pública Estadual Paulista, em parceria com a FUNDAP ofereceu aos diretores escolares o Curso PDG Educação: Gestão Escolar e a Política Educacional, semipresencial, nas Diretorias Regionais de Ensino e tendo como tutores desse curso os supervisores de ensino.

No segundo semestre de 2010 a Rede Pública Estadual Paulista em convênio com USP, a UNESP e a UNICAMP iniciaram as inscrições para REDEFOR - Programa Rede São Paulo de Formação de Docente; programados dezesseis cursos de especialização, treze nas disciplinas do currículo e três cursos de gestão. Os cursos foram oferecidos na modalidade a distância e contam com encontros presenciais.

No entanto, os aspectos denotados das características do que seja uma boa escolaridade, não são visíveis nas avaliações externas ocorridas na rede paulista, como por exemplo, nos resultados do SARESP e SAEB. Pode-se afirmar que os programas de formação continuada não vêm se concretizando na educação oficial paulista cujo problema carece de investigação sobre a perspectiva aprendida dos atores desse processo.

Em relação ao diagnóstico, a excessiva ênfase na ineficiência do Estado tornou-o mais ainda foco de críticas e de descaracterização de seu papel regulador no sistema de ensino público, não permitindo que entre outras variáveis sejam consideradas no processo.

Quanto aos prognósticos, percebe-se que as políticas implementadas pós-95 para garantir o acesso e a melhoria da qualidade de ensino, refletiram sobre o regime de progressão continuada, numa série de problemas relativos a déficits de aprendizagem que o próprio Sistema de Avaliação do Rendimento Escolar do Estado de São Paulo - SARESP identificou.

\section{A importância da ação supervisora como indutora do fortalecimento de formação dos profissionais da Educação da Rede Pública Estadual Paulista}

Daí pode-se pensar a relevância na atuação do supervisor de ensino, na assessoria as escolas e para alcançar o objetivo em conformidade com as Instruções Especiais SE - 3, de 114-2008 ${ }^{8}$, que define ação supervisora como sendo "a contribuição do supervisor de ensino para o aprimoramento do trabalho desenvolvido pela escola: docentes e gestores" bem como "identificar as necessidades de formação continuada da equipe escolar das escolas estaduais, procurando, de forma articulada, subsidiar o trabalho desenvolvido pela oficina pedagógica e professores - coordenadores".

${ }^{8}$ Este documento que regeu o Concurso Público de Prova e Títulos, para provimento de 372 cargos de supervisor de ensino da SEE/SP, em 2008.

RIAEE - Revista Ibero-Americana de Estudos em Educação, Araraquara, v. 15, n. esp. 4, p. 2777-2788, dez., 2020. e-ISSN: 1982-5587 
Desde os anos 50 a supervisão, sob a denominação de Inspeção Escolar, existe no sistema estadual de ensino paulista, de forma sistemática e com característica de mediadora entre a escola e administração superior do ensino, em continuidade às tarefas de inspeção de grupos escolares da década anterior que foram sendo ampliadas (APASE, 2004).

Em 1978, com a Lei Complementar 201/78, o Inspetor Escolar recebeu a denominação de Supervisor de Ensino. Além da nomenclatura de supervisor de ensino é significativo enfatizar o seu campo de atuação que representa o propositor e executor de políticas educacionais é, ao mesmo tempo, elemento de articulação e de mediação entre essas políticas e as propostas pedagógicas desenvolvidas em cada uma das escolas, exercendo, no sistema de ensino, as funções de assessorar, acompanhar, orientar, avaliar e controlar os processos educacionais bem como buscar, em conjunto com as equipes escolares, soluções e formas adequadas ao aprimoramento pedagógico e à consolidação da identidade da escola (APASE, 2004).

$\mathrm{Na}$ legislação estadual, o Decreto $\mathrm{n}^{\circ}$ 64.187/2019 que dispõe da reorganização da Educação, reforça as atribuições do supervisor de ensino em seu artigo 74 atuar articuladamente com o núcleo pedagógico na elaboração de seu plano de trabalho, na orientação e no acompanhamento do desenvolvimento de ações voltadas à melhoria da atuação docente e do desempenho dos alunos, à vista das reais necessidades e possibilidades das escolas.

Portanto, a função precípua do supervisor de ensino se efetiva na prática, quando este profissional consegue legitimar-se como uma das lideranças fundamentais para o desenvolvimento das políticas educacionais e consolidação das propostas pedagógicas das escolas (APASE, 2004).

Assim, na gestão escolar participativa os desafios e os conflitos, postos ao supervisor de ensino, indisciplina, violência, escassez de recursos humanos e materiais, defasagem de idade e série, evasão, repetência entre outros são exemplos dos problemas e desafios que a supervisão enfrenta na orientação das possibilidades de sanar os problemas diagnosticados em cada escola, que possui sua identidade, mesmo fazendo parte de uma rede.

Outro princípio norteador da ação supervisora pauta-se para analisar o Índice de Desenvolvimento da Educação do Estado de São Paulo (IDESP) ${ }^{9}$ das unidades escolares,

${ }^{9}$ O IDESP (Índice de Desenvolvimento da Educação do Estado de São Paulo) é um indicador de qualidade das séries iniciais ( $1^{\mathrm{a}}$ a $4^{\mathrm{a}}$ séries) e finais $\left(5^{\mathrm{a}}\right.$ a $8^{\mathrm{a}}$ séries $)$ do Ensino Fundamental e do Ensino Médio. Na avaliação de qualidade das escolas feita pelo IDESP consideram-se dois critérios complementares: o desempenho dos alunos nos exames do SARESP e o fluxo escolar. O IDESP tem o papel de dialogar com a escola, fornecendo um diagnóstico de sua qualidade, apontando os pontos em que precisa melhorar e sinalizando sua evolução ano a ano (SEE/SP, 2008).

RIAEE - Revista Ibero-Americana de Estudos em Educação, Araraquara, v. 15, n. esp. 4, p. 2777-2788, dez., 2020. e-ISSN: 1982-5587 
efetuar o acompanhamento regular nas escolas bem como, identificando necessidades de formação continuada para todos os membros da equipe escolar.

Essa análise exige uma ação supervisora participativa com a direção da escola e, para que juntos, possam propor alternativas para a solução dos problemas por meio da valorização do trabalho coletivo visando uma supervisão a serviço de um ensino de qualidade. Para Muramoto $(2009$, p. 2) se traduz em "uma escola de qualidade direito de todos, tornou-se, portanto, a um só tempo, questão de natureza didático-pedagógica, técnico-administrativa e legal, socioeconômica e político-cultural".

Cabe destacar ainda outra ação, ao supervisor de ensino, ao efetuar regularmente visitas aos estabelecimentos escolares, participe de reuniões com os membros escolares, equipe gestora $^{10}$ e corpo docente, buscando, em parceria com os mesmos, formas mais adequadas de aprimoramento do trabalho escolar e consolidação da identidade escolar, "um processo permanente de reflexão-ação-reflexão- nova ação [...] construindo um reinventar a cada dia, um refletir a cada noite" (LUCCHESI,1999, p. 120).

Acredita-se que no processo de definição dos papéis dos agentes educacionais, para atuar nessa sociedade, faz-se necessária a orientação do supervisor de ensino enquanto mediador na construção da identidade da escola e, também, solicitar a Rede Pública Estadual Paulista formação continuada aos professores via parcerias com as universidades e ou capacitação oferecidas pela oficina pedagógica ao professor - coordenador de cada unidade escolar que será o multiplicador para os professores da sua escola.

A mudança do cotidiano escolar nas discussões ou (re)orientações em que o supervisor de ensino participar com a equipe gestora e os professores em cada unidade escolar, não podem ocorrer apenas com e para o diálogo, pois:

Dialogar é sempre uma palavra muito aceita, mas pouco praticada. Participar é outra palavra muito bem-dita, muito aplaudida e extremamente benquista. Mas é bem difícil de concretizar o que aspiramos com esses conceitos. É difícil conviver, dividir, aceitar as opiniões e decisões dos outros, sobretudo quando reconhecemos que somos herdeiros de uma cultura e tradição autoritária (NUNES, 2009, p. 36).

A partir da crítica, apresentada por Nunes (2009), torna-se de fundamental importância pensar ações que busquem o enfrentamento dos problemas de uma escola democrática.

O supervisor de ensino pode e deve, a nosso ver, propor o (re)planejamento da escola para redirecionar as ações na tomada de decisão, em conformidade com a situação de cada

${ }^{10}$ Equipe gestora constituída pelo diretor, vice-diretor e coordenador pedagógico.

RIAEE - Revista Ibero-Americana de Estudos em Educação, Araraquara, v. 15, n. esp. 4, p. 2777-2788, dez., 2020. e-ISSN: 1982-5587 
unidade escolar e, também, indicar para rede pública estadual paulista qual formação os profissionais da educação escolar necessitam para atuar no cotidiano da escola pública. Isso significa colocar a realidade no contexto mais amplo da democratização do ensino e da própria sociedade brasileira, assumindo a formação do educador em serviço como um meio e não como um fim em si.

Diante do exposto, a partir do conhecimento provisoriamente construído durante o nosso percurso acadêmico, aliado à nossa trajetória profissional como servidores públicos desta Rede Pública Estadual Paulista, refletir a atuação do supervisor de ensino no enfrentamento do cotidiano escolar representa uma contribuição e um grande desafio na orientação assertiva dos profissionais da educação.

Embora a questão de formação em serviço esteja tão presente nos dias atuais, exige do supervisor de ensino um pensamento reflexivo a respeito das dificuldades e dos dilemas enfrentados pelo educador contemporâneo. Deve ser entendida como um “[...] pensamento que abrange as operações de busca, de pesquisa e de investigação [...]” (DEWEY, 1959, p. 14) referentes à construção de seu papel na sociedade, bem como sua participação no contexto sociocultural que envolve o universo escolar.

\section{Considerações finais}

Finalmente, acreditamos ser relevante investigar a contribuição da atuação do supervisor de ensino ao analisar a importância dessa atuação ao provocar nos profissionais da educação reflexão da proposta de formação continuada oferecida pela Rede Pública Estadual Paulista.

Nesta perspectiva de atuação a re(ação) do supervisor de ensino na orientação dos profissionais da educação para aprimorem a prática pedagógica, para que isso ocorra é pertinente repensarmos as políticas educacionais implantadas para essa finalidade, pois a formação como essa perpassará por várias dimensões da cultura escolar, como define Dominique Julià (1993,p. 1):

Um conjunto de normas que definem os saberes a ensinar e as condutas a inculcar um conjunto de práticas que permitem a transmissão desses saberes e a incorporação desses comportamentos, saberes e práticas estão ordenadas de acordo com as finalidades que podem variar segundo as épocas, as finalidades religiosas, sociopolíticas ou simplesmente de socialização. Normas e práticas não podem ser analisadas sem se levar em conta o corpo profissional, os agentes que são obrigados a obedecer a essas normas e, portanto, a pôr em obra os dispositivos pedagógicos encarregados de facilitar a sua aplicação, a saber, os professores.

RIAEE - Revista Ibero-Americana de Estudos em Educação, Araraquara, v. 15, n. esp. 4, p. 2777-2788, dez., 2020. e-ISSN: 1982-5587 
Dominique Julià (1993) reforça a ideia de o educador conhecer o contexto escolar, ou seja, a cultura escolar de fato e atuar como profissional da educação. Daí a importância do supervisor de ensino de oferecer formação aos profissionais da educação como demonstrado pela LDB/96 e de alguns estudos acerca da formação docente e da prática pedagógica.

Conclui-se que os desafios em voltas da ação supervisora junto a formação dos profissionais da educação pode contribuir para a melhoria da qualidade de ensino oferecido aos alunos das escolas públicas, uma vez que ao acesso e permanência na escola pública já foram garantidos quase em sua totalidade e pode fortalecer o oferecimento de uma escola com mais qualidade de ensino.

\section{REFERÊNCIAS}

ABDALLA, M. de F.; GALVÃO, V. S. Formação de professores para as séries iniciais do ensino fundamental. In: CONGRESSO ESTADUAL PAULISTA SOBRE FORMAÇÃO DE EDUCADORES, 9., 2007, Águas de Lindóia. Anais [...]. Águas de Lindóia: UNESP, 2007.

APASE. Sindicato de Supervisores do Magistério no Estado de São Paulo. SAS: subsídios à ação supervisora. São Paulo: SPEL Gráfica e Editora Ltda, 2004.

BRASIL. Lei n. 9.394, de 20 de dezembro de 1996. Lei de Diretrizes e Bases da Educação Nacional. Diário Oficial da União: Seção 1, Brasília, DF, n. 248, p. 27833, 23 dez. 1996.

CASASSUS, J. Tarefas da educação. Campinas: Autores Associados, 1995.

DOURADO, L. F.; OLIVEIRA, J. F. A qualidade da educação: perspectivas e desafios. Cad. Cedes, Campinas, v. 29, n. 78, p. 201-215, maio/ago. 2009. DOI:

https://doi.org/10.1590/S0101-32622009000200004

JULIÀ, D. A. A cultura escolar como objeto histórico. Revista Brasileira de História da Educação, Maringá, v. 1, n. 1, p. 9-43, 2001.

LIBÂNEO, J. C. Organização e gestão da escola: teoria e prática. Goiânia: Editora Alternativa, 2008.

LUCCHESI, M. A. S. Buscando novos caminhos para a supervisão. In: ALONSO, M. (Org.). O trabalho docente: teoria \& prática. São Paulo: Pioneira, 1999.

MELLO, G. N. Cidadania e competividade: desafios educacionais do terceiro milênio. 6. ed. São Paulo: Cortez, 1993.

MURRIE, Z. Caderno do Gestor. São Paulo :SEE/SP, 2008. n. 1.

NEUBAUER, R. Descentralização no Estado de São Paulo. In: COSTA, V. L. C. (Org.). Descentralização da Educação: novas formas de coordenação e financiamento. São Paulo: FUNDAP, Cortez, 1999.

RIAEE - Revista Ibero-Americana de Estudos em Educação, Araraquara, v. 15, n. esp. 4, p. 2777-2788, dez., 2020. e-ISSN: 1982-5587 
NUNES, C. Gestão Educacional, relações de poder e novos sujeitos sociais. In: SIMPÓSIO DO LABORATÓRIO DE GESTÃO EDUCACIONAL, 7., 2009, Campinas. Anais [...]. Campinas, SP: FE/UNICAMP, 2009.

PRADO, G. V. T. Ensino Fundamental de nove anos: currículo e expectativas de aprendizagem. In: SIMPÓSIO DO LABORATÓRIO DE GESTÃO EDUCACIONAL, 7., 2009, Campinas. Anais [...]. Campinas, SP: FE/UNICAMP, 2009.

SANDER, B. Gestão da Educação na América Latina: construção e reconstrução do conhecimento. 2. ed. São Paulo: Cortez, 1997.

SÃO PAULO (Estado) Secretaria da Educação. Comunicado SE de 05-12-2000.

SÃO PAULO (Estado) Secretaria da Educação. Coordenadoria de Estudos e Normas Pedagógicas. A construção da proposta pedagógica da escola. São Paulo: SE/CENP, 2000.

SÃO PAULO (Estado) Secretaria da Educação. Decreto n. 64.187/2019. Dispõe da reorganização a Secretaria da Educação e dá providências correlatas. Diário Oficial: São Paulo, DF, p. 3, 18 abr. 2019.

SÃO PAULO (Estado) Secretaria da Educação. Descentralização e reformas no Ensino Fundamental: unindo para construir com sucesso, uma escola de cara nova para São Paulo. São Paulo: Secretaria de Estado de Educação, FUNDAP, 1997. v. 2.

SÃO PAULO (estado). Instruções Especiais SE n. 03/2008, de 11 abr. 2008. Concurso público de prova e títulos, de 372 (trezentos e setenta e dois) cargos, e outros que vierem a surgir no decorrer do prazo de validade do concurso de Supervisor de Ensino - SQC - IIQM, da classe de suporte pedagógico do quadro do magistério da Secretaria de Educação do Estado de São Paulo. Diário Oficial: São Paulo, SP, 12 abr. 2008.

SÃO PAULO (estado). Lei complementar estadual n. 744, de 28 de dezembro de 1993. Institui vantagens pecuniárias para os integrantes da classe de supervisor de ensino, do quadro do magistério, e dá outras providências. Diário Oficial: São Paulo, SP, p. 7, 29 dez. 1993. PLC 61/1993

SÃO PAULO (estado). Resolução SE 76, DE 7-11-2008. Dispõe sobre a implementação da Proposta Curricular do Estado de São Paulo para o Ensino Fundamental e para o Ensino Médio, nas escolas da rede estadual. Diário Oficial: São Paulo, SP, 8 nov. 2008.

\section{SECRETARIA DE ESTADO DA EDUCAÇÃO. PEC/FOR PROF - Formação de}

Professores em exercícios: curso especial de formação de professores de $1^{\mathrm{a}}$ à $4^{\mathrm{a}}$ séries do Ensino Fundamental. Programa de Educação Continuada. Governo do Estado de São Paulo, 15 fev. 2001.

VIEIRA, S. L. Escola-função social, gestão e política educacional. In: FERREIRA, N. S.; AGUIAR, M. A. S. (Org.). Gestão da Educação: impasses perspectivas e compromissos. São Paulo, Cortez, 2001. 


\section{Como referenciar este artigo}

MARTINS, C. M. C.; CEDRAN, P. C. A supervisão de ensino como indutora do fortalecimento na formação continuada dos profissionais da educação da rede pública estadual paulista. Revista Ibero-Americana de Estudos em Educação, Araraquara, v. 15, n. esp. 4, p. 2777 2788, dez., 2020. e-ISSN: 1982-5587. DOI: https://doi.org/10.21723/riaee.v15iesp4.14535

Submetido em: 10/09/2019

Revisões requeridas: 10/01/2020

Aprovado em: 30/04/2020

Publicado em: 01/12/2020 